\title{
DIÁLOGO INTERARTES: O FILME O CONVENTO DE MANOEL DE OLIVEIRA E O ROMANCE AS TERRAS DO RISCO DE AGUSTINA BESSA- LUÍS
}

INTERARTS DIALOGUE: THE FILM "O CONVENTO" BY MANOEL DE OLIVEIRA AND THE NOVEL "AS TERRAS DO RISCO" BY AGUSTINA BESSA-LUISS

Cristiane Costa Baiotto Universidade Federal de Minas Gerais

RESUMO: O trabalho tem por objetivo estudar o diálogo que o cinema de Manoel de Oliveira estabelece com a ficção da escritora portuguesa Agustina Bessa-Luís. A partir do filme "O convento" que teve como argumento o romance "As terras do risco", pretende-se discutir as possibilidades de transcriação de uma linguagem para outra.

PALAVRAS-CHAVE: cinema; literatura; transcriação

ABSTRACT: The work aims to study the dialogue that Manoel de Oliveira's film sets with the fiction of the Portuguese writer Agustina Bessa-Luís. From the film "O convento", which had as its argument the novel "As terras do risco" , it is intended to discuss transcreational possibilities of a language to another.

KEYWORDS: cinema; literature; transcreation

A filmografia de Manoel de Oliveira pode ser pensada a partir do diálogo interartes, estabelecido, principalmente, com a literatura. A prática de se valer do texto literário para criar seus filmes é bastante emblemática, por isso, da grande parceria que o cineasta estabeleceu com a escritora portuguesa Agustina Bessa-Luís, resultou a criação de sete filmes motivados por cinco romances, um conto e um roteiro da autora. São eles: os romances Fanny Owen (1979), Vale Abraão (1991), As terras do Risco (1994), Joia de família (2001), A alma dos ricos (2002), o conto A mãe de um rio (1971) e o roteiro Garden-Party dos Açores (1996). Os filmes de Manoel de Oliveira que tiveram como argumento esses textos de Agustina são, respectivamente, Francisca (1981), Vale Abraão (1993), O convento (1995), O princípio da incerteza 


\section{Revista do SELL}

v. 5 , no. 2

ISSN: $1983-3873$

(2002), Espelho mágico (2005), Inquietude (1998), Party (1996) e Visita ou Memórias e Confissões (1982) 1 .

A relação entre cinema e literatura suscita diversas discussões acerca da adaptação. Isso porque, ainda que o cinema tenha em comum com a literatura a composição de uma narrativa, a passagem de um código para outro se processa de maneira multifacetada. A questão da adaptação cinematográfica é bastante complexa, pois diferente da análise binária sugerida pelos critérios estabelecidos na noção de "fidelidade", a relação interartes desencadeia diversos questionamentos acerca das potencialidades contidas em cada linguagem.

Segundo Robert Stam², a força que a busca pela "fidelidade" adquiriu ao longo da história da adaptação, a qual sempre foi entendida como tradução literal, pode ser justificada pelo viés que a crítica utilizava para "validar" o trabalho do cineasta com a linguagem cinematográfica, ou seja, o objetivo era chegar, novamente, ao texto, por meio do filme. $E$ isso, durante algum tempo, colocou o cinema como uma arte dependente da literatura, pois sempre tomava de empréstimo seu material.

No entanto, à medida que o filme foi se desvencilhando, pela própria crítica cinematográfica, das algemas do texto, a adaptação passou a ser vista como uma proposta de leitura pela linguagem que é própria do cinema. Afinal,

podemos questionar até mesmo se a fidelidade estrita é possível. Uma adaptação é automaticamente diferente e original devido à mudança do meio de comunicação. A passagem de um meio unicamente verbal como o romance para um meio multifacetado como o filme, que pode jogar não somente com palavras (escritas e faladas), mas ainda com música, efeitos sonoros e imagens fotográficas animadas, explica a pouca probabilidade de uma fidelidade literal, que eu sugeriria qualificar até mesmo como indesejável. ${ }^{3}$

\footnotetext{
${ }^{1}$ Esse filme é uma adaptação do texto $A$ visita de Agustina Bessa-Luís. Essa fita possui a seguinte chancela: "Por vontade expressa do realizador, este filme só pode ser publicamente exibido após a sua morte." O negativo e a fita estão em posse da Cinemateca Portuguesa. MARGARIDO. Manoel de Oliveira, p. 209.

2 STAM. A literatura através do cinema, p. 20.

${ }^{3}$ STAM. A literatura através do cinema, p. 20.
} 


\title{
Revista do SELL
}

v. 5 , no. 2

ISSN: $1983-3873$

A relação entre cinema e literatura, nesse sentido, passa a ser vista como uma forma produtiva para ambas as artes, pois promove a recriação do texto por meio da técnica do cinema. Assim, o filme constitui outra experiência com a linguagem que se difere daquela experimentada com a literatura. $O$ que está proposto à nossa reflexão é a relação entre as artes e seu diálogo. Essa discussão foi muito bem apresentada por Robert Stam, ao afirmar que "da mesma forma que qualquer texto literário pode gerar uma infinidade de leituras, assim também qualquer romance pode gerar uma série de adaptações." ${ }^{4} \mathrm{O}$ exercício da adaptação fílmica, nesse sentido, se assemelha, alegoricamente, ao trabalho de Pierre Menard ao "escrever" Quixote, pois ele

\begin{abstract}
Não queria compor outro Quixote - o que é fácil - mas o Quixote. Inútil acrescentar que nunca enfrentou uma transcrição mecânica do original; não se propunha copiá-lo. Sua admirável ambição era produzir algumas páginas que coincidissem - palavra por palavra e linha por linha - com as de Miguel de Cervantes. ${ }^{5}$
\end{abstract}

O engenhoso projeto de Pierre Menard, embora interpretado tradicionalmente como um trabalho de tradução textual, propõe duas tarefas acerca das quais pretendemos discutir no ofício de recriação da obra literária para o cinema, quais sejam: a cópia e a coincidência. Em seu projeto, Pierre Menard não se propunha copiar Cervantes, mas produzir páginas coincidentes.

Como vimos, muitas vezes, dentro da linguagem tradicional da crítica, a adaptação de uma obra literária para o cinema é analisada por meio da "fidelidade" que o filme mantém com o romance. Seria, portanto, a "cópia", ou seja, a mera reprodução de uma narrativa. Essa maneira de pensar a adaptação fílmica se dá por diversos fatores, desde os mais pessoais que envolvem o gosto do leitor por determinadas interpretações do romance, que serviu de argumento para o filme, até a forma de apresentação da progressão da narrativa no cinema. No entanto, a "cópia" ou a análise da "fidelidade" entre

\footnotetext{
${ }^{4}$ STAM. A literatura através do cinema, p. 21.

${ }^{5}$ BORGES. Edición crítica, p. 844. " no quería componer otro Quijote - lo cual es fácil - sino el Quijote. Inútil agregar que no encaró nunca una transcripción mecánica del original; no se proponía copiarlo. Su admirable ambición era producir unas páginas que coincidieran - palabra por palabra y línea por línea - con las de Miguel de Cervantes."
} 


\section{Revista do SELL}

v. 5 , no. 2

ISSN: $1983-3873$

filme e texto não nos servem como princípio metodológico, já que tratamos de linguagens distintas e de contexto de produção diverso.

Assim, quando pensamos no trabalho de Pierre Menard, encontramos em seu objetivo uma sutileza que determina a relação da literatura com 0 cinema. Afinal, ele reconhecia que seu trabalho de aproximação com a obra de Miguel de Cervantes já pressupunha a diferença. Sendo assim, o filme que se originou de um romance não o copia, mas coincide com ele, pois a coincidência deixa aparecer alguma semelhança, porém sem a pretensão de ser igual. Esse exercício seria, então, uma forma de transcriação.

Essa abordagem da transcriação consiste no trabalho da tradução como criação, ou seja, o romance não é, simplesmente, filmado, mas seu enredo é trabalhado como possibilidade aberta à recriação. Há, portanto, um cuidado com a reconstituição da informação estética. Nesse contexto, a tradução opera de maneira distinta àquela que se apresentava como réplica aproximativa e visava transpor o livro para o filme.

Aqui, tomamos por empréstimo o conceito de transcriação que Haroldo de Campos $^{6}$ desenvolve na teoria da tradução literária cujo princípio é a impossibilidade de uma tradução sem que ocorra a recriação do texto.

Afinal, a "informação estética" 7 , como define Haroldo de Campos, é a organização dos signos para a construção de um conteúdo semântico. Dessa maneira, uma mesma informação pode ser transmitida por meio de diferentes estruturas de signos. Assim, o trabalho do tradutor é entender a essência significativa do texto e ser capaz de (re)imaginar sua informação estética para criar o texto dentro do novo idioma.

Tais considerações estão presentes no artigo $A$ tarefa do tradutor, de Walter Benjamin, ${ }^{8}$ no qual 0 autor assemelha o trabalho do tradutor com 0 cuidadoso exercício de juntar os cacos de um vaso quebrado, que para

se poderem reajustar, têm de encaixar uns nos outros nos mais pequenos pormenores, embora não precisem de ser iguais, assim também a tradução, em vez de querer assemelhar-se ao

${ }^{6}$ CAMPOS. Metalinguagem e outras metas.

${ }^{7}$ CAMPOS. Metalinguagem e outras metas, p. 34.

${ }^{8}$ BENJAMIN. A tarefa do tradutor. 


\section{Revista do SELL}

v. 5 , no. 2

ISSN: $1983-3873$

sentido do original, deve antes configurar-se, num ato de amor e em todos os pormenores, de acordo com o modo de querer dizer desse original, na língua da tradução, para assim tornar ambos, original e tradução, reconhecíveis como fragmentos de uma língua maior, tal como os cacos são os fragmentos do vaso inteiro. ${ }^{9}$

Essa tarefa do tradutor de lidar com os pormenores, visando 0 potencial de recriar sobre a obra, é o eixo central do procedimento transcriador que aumenta e reconfigura os recursos de expressão em uma rede intertextual. A transcriação consiste, portanto, na tradução como criação, ou seja, não se filma o romance, mas se trabalha sua história como possibilidade aberta à invenção.

Nesse contexto, um dado importante sobre o filme $O$ convento, de Manoel de Oliveira, e o romance As terras do risco, de Agustina Bessa-Luís, é a forma como se processou essa transcriação. Certa vez,

Oliveira [pediu] a Agustina uma "história" para um filme ou um "romance" para um filme. Agustina começou a escrever Pedra de toque, situado no Convento da Arrábida, ao sul de Lisboa, uma das paisagens mais misteriosas e mágicas de Portugal. Sabendo que Oliveira pensava em Catherine Deneuve e Gérard Depardieu para os papéis principais, guiou-se pelas imagens deles para os protagonistas. Mas o livro demorou e Oliveira queria começar a filmar. Pediu, pois, a Agustina que Ihe resumisse a "história" [...] e, com base no resumo que a escritora the fez [...] elaborou, ele próprio, o roteiro. [...] $]^{10}$

O romance foi resumido para ser transcriado para o filme, e, foi escrito e elaborado em torno dos dois personagens principais, concebidos a partir das características dos atores selecionados pelo cineasta. Esse processo criativo ocorreu em paralelo, originando um procedimento inusitado de transcriação, pois essa composição simultânea, diferente das demais, ultrapassa as fronteiras convencionais da adaptação fílmica e exprime outra lógica para o processo criativo.

\footnotetext{
${ }^{9}$ BENJAMIN. A tarefa do tradutor, p. 93.

10 COSTA, João Bénard. Pedra de toque o dito "eterno feminino" na obra de Manoel de Oliveira, p. 144.
} 


\section{Revista do SELL}

v. 5 , no. 2

ISSN: $1983-3873$

Por meio da potencialidade criativa contida nesse processo, podemos refletir acerca do diálogo interartes. A interação do cinema com a literatura recria esse espaço dialógico e produtivo do projeto transcriador, pois o filme não segue um roteiro ou orientação contida no texto, mas dialoga com ele. Quando o cineasta se vale do romance, ele o faz para recriá-lo sob sua própria ótica. Portanto, "o livro e o filme nele baseado são vistos como dois extremos de um processo que comporta alterações de sentido [...]"11

Oliveira filmou aquilo que memorizou do resumo que lhe foi dado. Assim, o que nos parece mais interessante para o diálogo entre as artes, além dessa "fantástica história,"12 é justamente a lacuna presente nesse processo criativo: um filme adaptado de um resumo do romance.

Dessa maneira, o eixo essencial para pensar a adaptação fílmica é esse espaço engendrado pela "nova" linguagem, que absorve o texto e, ao mesmo tempo, o prolonga, é a própria imagem palimpsêstica. Os pergaminhos, reaproveitados para novas escrituras, ensejam bem mais que a técnica de reutilizar um material, pois possibilitam pensar essa relação por meio da interação e do diálogo.

Nos palimpsestos as palavras estavam à sombra de outras e, quanto mais escrita, mais sombras. Dessa maneira, podemos fazer uma analogia ao processo de transcriação do texto para o filme. A linguagem do cinema é composta por uma "gramática" própria, pois exige uma técnica, ou uma ciência do "como fazer". A técnica atrelada ao estilo do seu produtor é arte, é expressão. E se o cinema e o livro possuem "diferenças abismais" também possuem semelhanças, as quais residem na expressividade do ato criativo engendrado na composição palimpsestica. Afinal, "o pensamento, através da

\footnotetext{
${ }^{11}$ XAVIER. Do texto ao filme: a trama, a cena e a construção do olhar no cinema, $p$. 61.

${ }^{12}$ COSTA, João Bénard. Pedra de toque o dito "eterno feminino" na obra de Manoel de Oliveira, p. 144.
} 


\section{Revista do SELL}

v. 5 , no. 2

ISSN: $1983-3873$

palavra, é também imagem. Pois não resulta da palavra uma imagem das coisas?"13

Dessa maneira, no romance As terras do risco, de Agustina Bessa-Luís, e no filme $O$ convento, de Manoel de Oliveira, o insondável e o compreensível; o abismal e o conhecível; o bem e o mal se apresentam como forças misteriosas que estabelecem tensões entre o sujeito e o mundo exterior. Essas forças antitéticas se infiltram na rotina do convento e se manifestam em diversos momentos, de diferentes formas, em um jogo espelhado entre as personagens femininas.

O eixo central de ambas as histórias é o fato de um professor francês, acompanhado por sua esposa, ir à Serra da Arrábida, em Portugal, com o objetivo de pesquisar a origem de Shakespeare, que segundo ele, não seria um inglês, mas um judeu espanhol. Tal suspeita foi levantada a partir da leitura do documento de casamento de Isabel de Lancaster com o Duque de Borgonha, no qual havia a assinatura de uma das testemunhas cujo nome era Heitor Sequespee. Desde então, o professor se empenhou em "eliminar Shakespeare do número de gênios ingleses."14

O fato que levou o professor ao convento foi o desejo de desvendar a verdadeira origem de Shakespeare. E essa é uma imagem fundamental para pensarmos processo transcriativo. Afinal, qual é a origem do filme? O romance ou o resumo? E o que dizer do romance que teve como base as personagens escolhidas para o filme? Em meio a esse processo dialógico a origem se perde.

Nesse sentido, o recurso essencial no cinema de Oliveira não está na palavra transformada em imagem, mas no jogo que se é possível estabelecer, justamente, pela existência de uma lacuna nessa tradução, que corresponde ao processo criativo. Nesse espaço lacunar está a possibilidade de transcriação interpretativa do romance que, para ser recriado no filme, desencadeia uma série de relações que se implicam mutuamente na interação literária e fílmica.

${ }^{13}$ OLIVEIRA, Um concerto em tom de conversa. 2007, p. 28.

${ }^{14}$ BESSA-LUÍS. As terras do risco, p. 13. 


\section{Revista do SELL}

v. 5 , no. 2

ISSN: $1983-3873$

Nesse sentido, a transcriação do romance para o filme não significa uma ruptura com o texto que serve de argumento, mas um processo (ou a relação hipertextual, a partir da qual, de um hipotexto, emerge um hipertexto e, assim, a composição de uma rede dialógica, segundo Genette ${ }^{15}$ ) que promove a fusão ou a (inter)relação de superfícies significativas, dentro do qual surge uma nova harmonia que

permite verificar como a questão da "fidelidade" não pode ser reduzida à pobreza de um conceito de transposição "literal", mas deve antes ser considerada como a fecunda e inovadora (re)criação interpretativa de quem se identificou previamente com a obra literária. ${ }^{16}$

A (re)criação interpretativa da obra literária é uma das formas pela qual podemos compreender a maneira que Manoel de Oliveira dialoga com os romances de Agustina Bessa-Luís. De modo geral, os romances da escritora apresentam uma articulação personagem/espaço/enredo bastante complexa. "[...] a construção do livro de Agustina Bessa-Luís, é muito difícil, muito literária." 17 Nesse sentido, a relação interartes desencadeia um processo, contínuo, de interpretação criativa que desmonta e renova as estruturas sígnicas.

O cineasta afirma que "o filme não é o livro", ${ }^{18}$ mas é preciso encontrar a forma do texto no roteiro, "ver até onde é possível ir, sem perder, no entanto, o mínimo do que é necessário dizer." ${ }^{19}$ Esse trabalho com o texto literário é a qualidade interpretativa que viabiliza o diálogo, pois "quando o diretor opta por uma adaptação, não inventa a história, mas a forma de contá-la em um outro veículo, outro suporte, outros sentidos."20

É interessante observar, aqui, que o sentido dessa relação não está preso em apenas um ponto fixo, literário ou cinematográfico, mas no trabalho interpretativo e na possibilidade de traduzir criativamente, de aproximar estruturas distintas e, por meio delas, criar uma rede, um palimpsesto.

${ }^{15}$ GENETTE. Palimpsestes la littérature au second degré. 1982.

${ }^{16}$ LUPI BELO. Mrs. Dalloway: da narrativa literária à narrativa fílmica, p. 6.

17 BAECQUE; PARSI. Conversas com Manoel de Oliveira, p. 90.

${ }^{18}$ OLIVEIRA, Manoel. Os artifícios da memória. In: Manoel de Oliveira, 2005, p.65.

${ }^{19}$ BAECQUE; PARSI. Conversas com Manoel de Oliveira, p. 78-79.

${ }^{20}$ CRUZ. Manoel de Oliveira: literatura e cinema, p. 188. 


\section{Revista do SELL}

v. 5 , no. 2

ISSN: $1983-3873$

Nessa rede, imagem e palavra são perpassadas por diversas inscrições, e isso não implica dizer de equivalências, mas de apropriação de sentido. Ou seja, ocorre uma transcriação das formas, um jogo entre os elementos conceituais e perceptivos.

Para Oliveira, esses elementos compõem um esquema figurativo da sua atual

visão desse monumento, que é o cinema, o qual representaria por quatro colunas suportando um pórtico, à maneira de um templo grego. A primeira coluna seria a da imagem, a segunda, a da palavra, a terceira, a do som, e a quarta, a da música; o pórtico frontal que sustentam representaria a ideia geradora que lhes dá sentido e unidade. ${ }^{21}$

Nesse engenhoso jogo semiótico, que Oliveira propõe para pensarmos o cinema, está o cruzamento das "matrizes da linguagem"22 proposto por Lucia Santaella. ${ }^{23}$ Segundo a autora, todas as linguagens, bem como os meios e canais pelos quais elas veiculam, estão alicerçadas em três matrizes, as quais seriam: o verbal, o visual e o sonoro e "toda a variedade de processos sígnicos que eles geram"24.

A linguagem visual diz respeito às "formas visuais estruturadas como linguagem," ${ }^{25}$ e nesse sentido, vale ressaltar a hipótese de que a realização da visualidade está na forma. A matriz visual corresponde, portanto, à representação do mundo visível por meio de formas inteligíveis, ou seja, pela apresentação ou representação de imagens perceptivas, portanto imagens fixas, "não-temporalizadas".

${ }^{21}$ OLIVEIRA. Esta minha paixão, p. 172.

${ }^{22} \mathrm{~A}$ autora apresenta a elaboração de um sistema no qual os conceitos peircianos são tomados como base para uma categorização do modo pelo qual o verbal, o visual e o sonoro se manifestam. Nesse sentido, é interessante abordarmos essa concepção das linguagens híbridas, pois o sistema descrito por Santaella trata dos processos concretos de revelação dessas linguagens e suas misturas.

${ }^{23}$ SANTAELLA, Lucia. Matrizes da linguagem e do pensamento.

${ }^{24}$ SANTAELLA, Lucia. Matrizes da linguagem e do pensamento, p. 29.

${ }^{25}$ SANTAELLA, Lucia. Matrizes da linguagem e do pensamento, p. 186. 


\section{Revista do SELL}

v. 5 , no. 2

ISSN: $1983-3873$

O cinema, no entanto, seria uma linguagem híbrida, pois sua realização pressupõe o visual, o sonoro e o verbal.

Isso se explica porque colocar as imagens em movimento significa impregná-las de tempo, cuja ordem de inteligibilidade se encontra no princípio de sequência que aparece tanto na música quanto no verbal. ${ }^{26}$

As matrizes sonora e verbal se aproximam, justamente, pelo "conjunto de regras que permitem o funcionamento dos sistemas musicais quanto pela natureza temporal do desenvolvimento dos sons na música e na fala." ${ }^{27}$ Assim, a gramática da língua e a estrutura dos sons, na música, possuem uma relação de composição de sentido, examináveis em cada forma de experiência, de expressão.

Aqui, é importante ressaltar uma distinção, feita por Lucia Santaella, em relação à linguagem verbal presente no cinema: o nível verbal dos diálogos e o nível verbal do roteiro. Os diálogos são compostos pela linguagem verbal oral, por isso se distinguem da forma, também verbal, porém, escrita do roteiro. Ambos são variações de discursividade da Matriz Verbal. Essa diferenciação é importante porque, "se for narrativo, o que, na imensa maioria das vezes, ele é, mesmo quando mudo, o cinema já traz também implícitas as características do verbal. Por isso mesmo, cinema pressupõe roteiro."28

Outra divisão importante, que Manoel de Oliveira estabelece dentro de seu sistema de produção fílmica, é entre a música e o som ${ }^{29}$, ou seja, há um universo de sons possíveis na linguagem cinematográfica, dentre os quais a música é apenas um. O cineasta, dessa maneira, apresenta uma sutileza no trato dos materiais sonoros.

No que diz respeito ao som, na concepção oliveiriana, apresenta, em sentido mais amplo, um universo de sonoridade natural, tais como: o vento, a água correndo nos rios, as árvores tocadas pelo vento, as ondas do mar, os

\footnotetext{
${ }^{26}$ SANTAELLA, Lucia. Matrizes da linguagem e do pensamento, p. 206.

27 SANTAELLA, Lucia. Matrizes da linguagem e do pensamento, p. 98.

${ }^{28}$ SANTAELLA, Lucia. Matrizes da linguagem e do pensamento, p. 386.

${ }^{29}$ Manoel de Oliveira, em diversos momentos, usa o termo som, como um divisor entre o cinema mudo e o cinema sonoro. Nesse caso, o som abrange todas as possibilidades que o advento dessa tecnologia proporcionou ao cinema.
} 


\section{Revista do SELL}

v. 5 , no. 2

ISSN: $1983-3873$

passos das pessoas dentro de determinado lugar, enfim, todos os sons que decorrem de um movimento, de uma ação. Já a música é um "tecer sonoro"30 que emerge de convenções. A música é composta por elementos combinatórios, arranjados com certa finalidade. No cinema, ela é uma linguagem híbrida da lógica visual, pois compõe sentido com a cena, e verbal pela relação significativa estabelecida entre os diálogos.

Essa variedade de processos sígnicos configura o hibridismo contido na linguagem cinematográfica, ou seja, o cinema é composto por esse cruzamento de linguagens, pois mistura as matrizes, verbal-visual-sonora, de maneira própria. A lógica semiótica está presente no cinema,

por se tratar de imagens em movimento, mesmo quando não acompanhado de trilha sonora ou de qualquer tipo de som, o cinema já traz a lógica da sonoridade dentro de si, na sintaxe das durações de planos, nos seus cortes, nos ritmos que impõe às sequências. ${ }^{31}$

Oliveira lança mão dessa estrutura semiótica perceptual no cinema para se desdobrar em uma experiência que eleva e problematiza essa estrutura. $O$ modo pelo qual o cineasta português concebe a imagem cinematográfica rompe com a representação indireta do tempo através do movimento. Os planos fixos, característicos de sua filmografia, correspondem ao privilégio que o cineasta atribui ao pensamento e à construção da cena com base na força significativa do diálogo. O diretor associa o movimento a uma manobra para distrair o público, e em uma cena, composta por um diálogo "rico", não há espaço para dispersar a atenção. Afinal, "dar forma ao pensamento é a expressão mais elevada do cinema"32

No filme $O$ convento, Uma cena de destaque é a que mostra o percurso do professor até a biblioteca. Baltar, o guardião, encarrega-se de mostrá-lo onde ficam os livros que Ihe ajudarão em sua pesquisa. Os dois andam por algumas partes do convento, entram em uma sala, em cuja parede frontal há uma estátua de um monge crucificado, que retém, por certo tempo, a

\footnotetext{
${ }^{30}$ SANTAELLA, Lucia. Matrizes da linguagem e do pensamento, p. 397.

${ }^{31}$ SANTAELLA, Lucia. Matrizes da linguagem e do pensamento, p. 386.

${ }^{32}$ OLIVEIRA. Esta minha paixão, p. 172.
} 


\section{Revista do SELL \\ v. 5 , no. 2}

ISSN: $1983-3873$

atenção do professor. Em sequência, há o close no rosto do professor que contempla diversas caveiras, dependuradas na parede, no interior da sala. E a câmera mostra em planos sequenciais o rosto do professor, as caveiras e Baltar. Logo, os dois saem por um corredor externo que dá acesso à biblioteca.

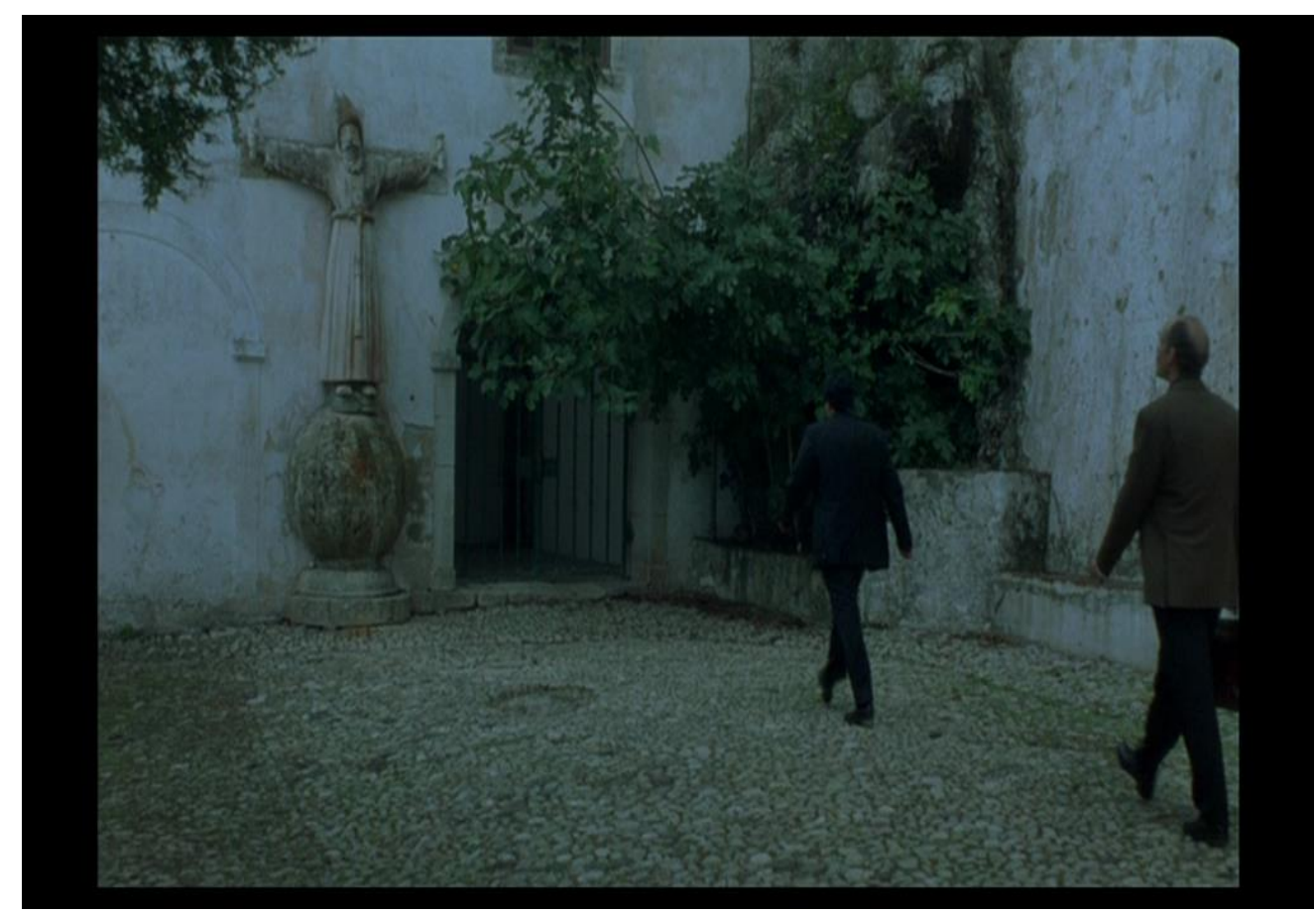

Figura 1- O professor e Baltar a caminho da biblioteca. A câmera fixa captura a passagem dos dois. 


\section{Revista do SELL}

v. 5 , no. 2

ISSN: $1983-3873$

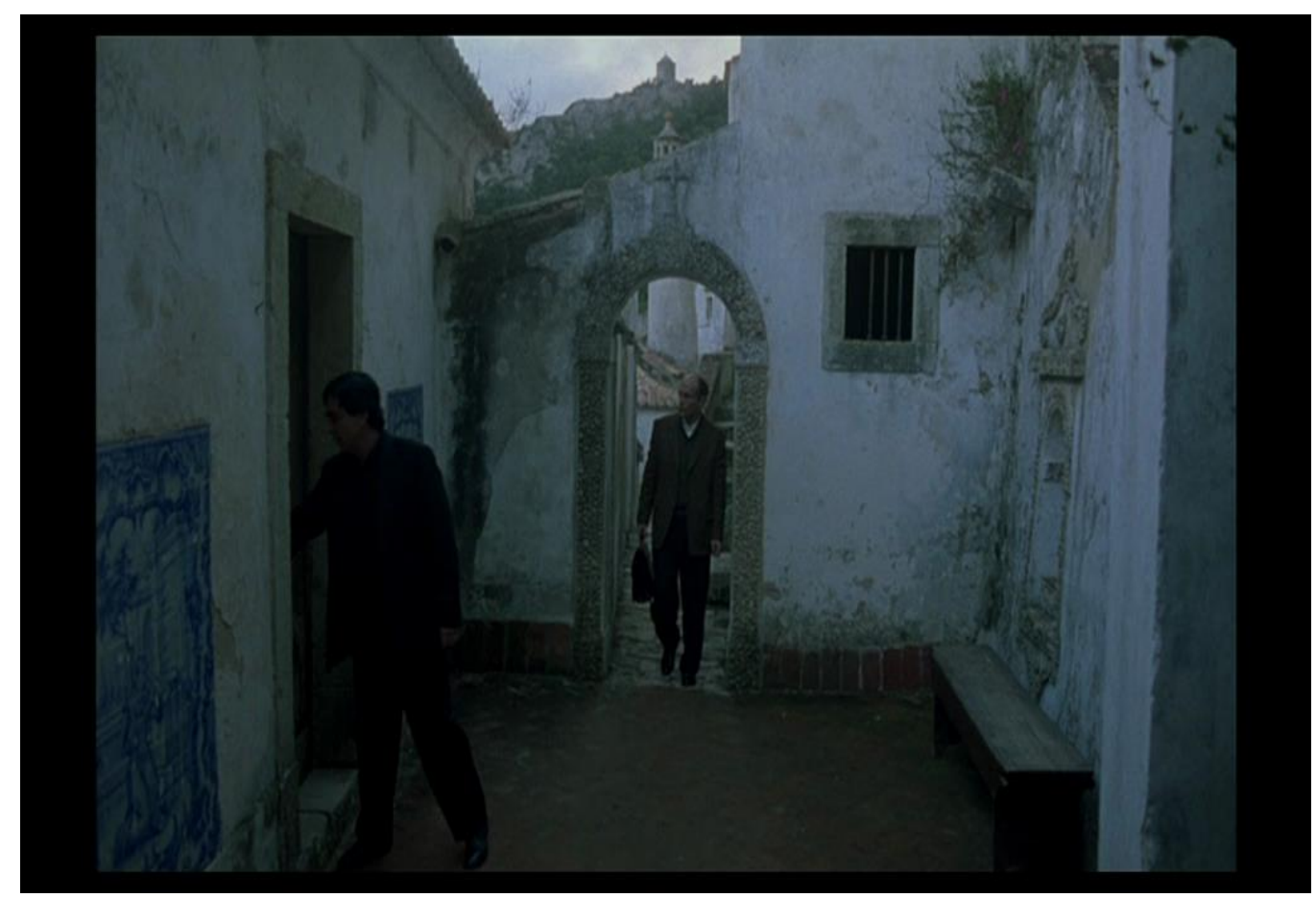

Figura 2- O convento (1995) - Os dois chegam à biblioteca. A saída da sala na qual o professor contempla as caveiras não é mostrada ao espectador. Em um corte, ambos aparecem diante da câmera fixa e adentram a biblioteca.

A composição da cena não é feita pela ótica da personagem, na qual os espectadores veem o que ele enxerga. No filme, a câmera fixa, com planos longos, está posicionada em determinadas partes do convento e os personagens passam por ela, como se o lugar imprimisse sua ótica. Nesse sentido, o potencial criativo da imagem está em sua fixidez que dialoga com algo que está além daquilo que é mostrado.

A câmera, em um ponto fixo, permite ver, mas também cria impossibilidades, buracos, falhas, e com isso, constrói-se uma imagem que não para de crescer em dimensões significativas, pois, aqui, a câmera não se contenta em seguir o movimento das personagens.

É evidente que o posicionamento da câmera, a duração dos planos e os cortes não são aleatórios, mas norteados pela escolha do diretor para compor a narrativa. No entanto, o que queremos ressaltar são as relações internas de uma imagem que não se fecha em si, mas se deseja sempre alargada, deslocada e produz diversas camadas de sentido em que, por vezes, a superfície é mais densa que a profundidade. Assim, 


\section{Revista do SELL}

v. 5 , no. 2

ISSN: $1983-3873$

os elementos da imagem [...] entram em relações internas que fazem com que a imagem inteira deva ser "lida", não menos que vista, legível tanto quanto visível. Para o olho do vidente, como do adivinho, é a "literalidade" do mundo sensível que o constitui como livro. ${ }^{33}$

A reversão da "imagem-movimento" para a "imagem-tempo", segundo Deleuze, acontece, justamente, nessa nova concepção da imagem que subordina os objetos, as personagens, o espaço, às "funções do pensamento". E, por isso, apresenta "uma nova concepção do quadro e dos reenquadramentos". ${ }^{34}$

O trabalho de Manoel de Oliveira com a imagem fílmica se processa, exatamente, nessa potência criadora que emerge dessa reversão, a qual possibilita uma ampliação, um alargamento do "composto imagem-tempo", em que o mais importante é a imagem como expressão, e expressão da alma.

Dessa maneira, Oliveira revela que, no plano fixo, tempo e movimento se equivalem, pois a força expressiva da imagem, por vezes, advém de sua fixidez. "E assim,/ a expressão vital -substância de toda arte- / se transforma a cada instante/ em substrato artístico/ no íntimo de cada ser./ E ali fica potencialmente conservado/ esse instante fugaz." ${ }^{35}$

Essa é a articulação, talvez a mais expressiva, que Manoel de Oliveira estabelece com os romances de Agustina Bessa-Luís. Esse modo poético, de operar o universo literário no cinema, em que o cineasta "pinta com palavras, sublinhadas nos sons e nos silêncios. O cinema se realiza de forma genial, reinventando com autenticidade e originalidade. ${ }^{36} \mathrm{E}$ possibilita uma significativa afinidade e um rico diálogo na maneira pela qual se configuram as relações entre cinema e literatura e entre escritora e cineasta.

\footnotetext{
${ }^{33}$ DELEUZE. A imagem - tempo, p. 34.

${ }^{34}$ DELEUZE. $A$ imagem - tempo, p. 34

${ }^{35}$ OLIVEIRA. Poema Cinematográfico, p. 190.

${ }^{36}$ CASIMIRO. Manoel de Oliveira. Não vou por aí, p. 110.
} 


\section{Revista do SELL}

v. 5 , no. 2

ISSN: $1983-3873$

\section{Referências}

AVELLA, Aniello Angelo (org.). Um Concerto em tom de conversa. Belo Horizonte: Editora UFMG, 2007.

BAECQUE, Antoine de; PARSI, Jacques. Conversas com Manoel de Oliveira. Porto: Campo das Letras, 1999.

BENJAMIN, Walter. Obras escolhidas I: Magia e técnica, arte e política. São Paulo: Brasiliense, 1985.

BESSA-LUÍS, Agustina. As terras do risco. Lisboa: Guimarães Editores. 1999.

BORGES, Jorge Luis. Edición Crítica, vol. I. Anotada por: Rolando Costa Picazo e Irmã Zangara. Buenos Aires: Emecé, 2009.

CAMPOS, Haroldo de. Metalinguagem e outras metas: ensaios de teoria e crítica literária. São Paulo: Perspectiva, 2010.

CASIMIRO, Manuel. Manoel de Oliveira. Não vou por aí. Camões: Revista de Letras e Cultura Lusófonas, n. 12-13, p. 110, jan./jun. 2001.

COSTA, João Bénard. Pedra de toque: o dito eterno feminino na obra de Manoel de Oliveira. In: MACHADO, Álvaro (Org.). Manoel de oliveira. São Paulo: Cosac Naify, 2005. p 117-164.

CRUZ, Jorge Luiz. Manoel de Oliveira: literatura e cinema. Comunicação e Informação, v. 7, n. 2: p. 188-195, jul./dez. 2004.

DELEUZE, Gilles. A imagem - movimento. São Paulo: Brasiliense,1983.

DELEUZE, Gilles. A imagem - tempo. São Paulo: Brasiliense, 1990.

GENETTE, Gérard. Palipsestes: La littérature au second degree. Éditions du Seuil, 1982.

LUPI BELO, Maria do Rosário. Mrs. Dalloway: da narrativa literária à narrativa fílmica. A visibilidade do momento. In: MACEDO, Ana Gabriela et al. (Org.). Intertextual Dialogues: Travels and Routes. Braga: Universidade do Minho; Departamento de Estudos Ingleses e Norte-Americanos; Instituto de Letras e Ciências Humanas, 2007. p. 93-103.

MARGARIDO, Orlando. Filmografia. In: MACHADO, Álvaro (org.). Manoel de Oliveira. São Paulo: Cosac Naify, 2005. p.194-236.

OLIVEIRA, Manoel. Esta minha paixão. In: MACHADO, Álvaro (Org.). Manoel de oliveira. São Paulo: Cosac Naify, 2005. p 167-173.

Poema Cinematográfico. : MACHADO, Álvaro (Org.). Manoel de oliveira. São Paulo: Cosac Naify, 2005. p 189-192. 


\section{Revista do SELL}

v. 5 , no. 2

ISSN: $1983-3873$

Os artifícios da memória. In: MACHADO, Álvaro (Org.). Manoel de oliveira. São Paulo: Cosac Naify, 2005. p 63-71.

SANTAELLA, Lucia. Matrizes da Linguagem e do Pensamento. São Paulo: lluminuras. 2005.

STAM, Robert. A literatura através do cinema. Belo Horizonte: Editora UFMG, 2005.

XAVIER, Ismail. Do texto ao filme: a trama, a cena e a construção do olhar no cinema. In: PELLEGRINI, Tânia. et al. Literatura, cinema e televisão. São Paulo: Editora Senac São Paulo, Instituto Itaú Cultural, 2003.

\section{Filme}

Oliveira, Manoel. O convento. Direção: Manoel de Oliveira. Portugal: Lusomundo.1995. 